\title{
The Spiral Organ Responsible for Producing Sound Signals, an Essential Taxonomic Character in the Phylogenetic Analysis of the Genus Hamadryas (Nymphalidae: Biblidinae): The Case of Hamadryas chloe chloe (Stoll) [1787] from South America
}

\author{
Luis Ricardo Murillo-Hiller \\ Sistema de Estudios de Posgrado en Biología, Escuela de Biología, Universidad de Costa Rica, 2060 San José, Costa Rica \\ Correspondence should be addressed to Luis Ricardo Murillo-Hiller, murillohiller@gmail.com
}

Received 24 January 2011; Accepted 6 March 2011

Academic Editor: E.-I. Izawa

Copyright ( 2011 Luis Ricardo Murillo-Hiller. This is an open access article distributed under the Creative Commons Attribution License, which permits unrestricted use, distribution, and reproduction in any medium, provided the original work is properly cited.

\begin{abstract}
Dissections and scientific illustrations were done of the spiral organ located in the forewing subcostal vein of $H$. chloe, which was compared with other Hamadryas species that produce audible sound signals. Important differences were found; for example, in $H$. chloe, this organ is split into many independent pieces called membrane discs, whereas in the others species, it consists of just a single spiral. Implications for systematic analysis are discussed, with support from observations on ecology, chorology, and male genitalia.
\end{abstract}

\section{Introduction}

Sound production has been reported for many genera and species of adult Lepidoptera. This occurs through various mechanisms, such as stridulating the "wing-leg" in Noctuidae, the "frenulum-retinaculum" in Pyralidae, the "valva-A8 segment" in Sphingidae, and "wings-thorax" in Cossidae [1]. Explanations for the function of sound production include courtship, defense, and territoriality [2-5].

In Hamadryas, sound production is due to an amplifier organ inside the subcostal vein of the butterfly forewings, connected to a membrane system located in the proximal area of the same wing $[4,6]$. Hamadryas species which have been studied to describe the mechanics of these structures include $H$. februa, $H$. guatemalena, $H$. glauconome, $H$. amphinome [4], and $H$. feronia $[4,6]$. These species have been shown to have a similar sound-production system, which consists of the swelling (by more than double the normal width) of the proximal half of the subcostal vein of the forewings, with a spiral structure located inside. This spiral increase in width from the distal end to the base and is composed of a continuous membrane that leads to a resonance box [4].

A species of Satyrinae, Yphthimoides castrensis, produces sounds with an organ similar to that of Hamadryas. It is located in the same vein and probably involves the Vogel's organ. The acoustic signals produced by this butterfly have similar characteristics to those of Hamadryas. This similarity probably represents an evolutionary convergence, since no phylogenetic relationship is thought to exist between these two groups. Y. castrensis, as in Hamadryas species, has a swollen subcostal vein, but it is eight times wider than the normal vein width. Inside the vein, instead of a spiral organ, Y. castrensis has a multichamber system of polygonal chambers that vibrate as an amplifier [5]. The total length of the Y. castrensis organ is $6 \mathrm{~mm}$ [5], whereas the Hamadryas spiral organ studied by Monge-Nájera et al. [4] has a total length of almost $20 \mathrm{~mm}$.

The objective of the present study is to describe the forewings and internal structure of the subcostal vein of $H$. chloe in order to propose useful criteria for phylogenetic analysis of the genus and other species with similar sound production organs. 


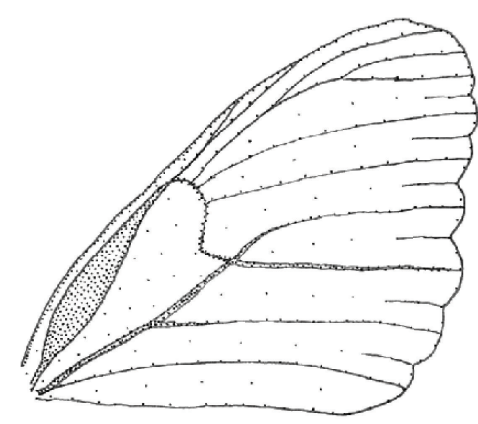

(a)

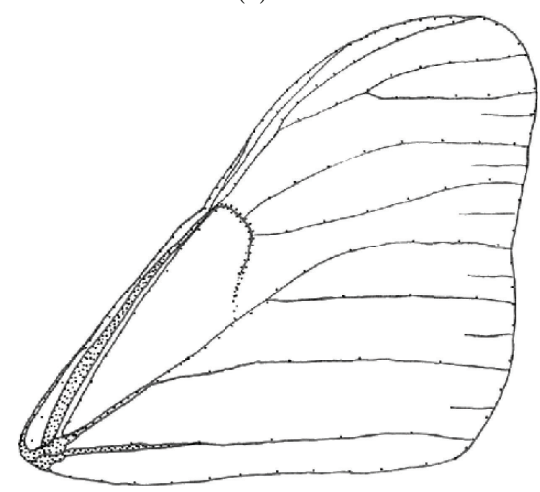

(b)

Figure 1: Right forewings of Hamadryas: (a) H. chloe and (b) $H$. guatemalena. Scale $1 \mathrm{~cm}$.

\section{Materials and Methods}

The spiral organs of Hamadryas species were examined in detail in order to find new taxonomic characters useful for phylogenetic analysis. Specimens from the following collections were studied: Museo Nacional de Costa Rica, Instituto Nacional de Biodiversidad, Museo de Insectos de la Universidad de Costa Rica, the private collections of Enrique Lorenzoni (Venezuela), Manuel Ortíz (España), and the author's collection.

A total of 224 specimens were analyzed, and only one of them was $H$. chloe chloe, which was identified by the author using the key in Jenkins [7]. This species is very rare in collections, because it has very local populations in South America and is difficult to find in its natural habitat [7]. The specimen studied is a male from Brazil, collected in the Reserva Forestal de Sacavém in San Luis, Maranhao, August 12, 1961, with no collector data. The specimen is deposited in the collection of the Museo de Insectos of the University of Costa Rica.

The ventral membrane of the subcostal vein of both forewings was removed using dissection equipment and a stereomicroscope, and the structure of the spiral organ inside was studied. Photographs were taken with a Nikon Coolpix 4500 , and drawings were done of the details. The dissected parts were mounted on pieces of cardboard and pinned with the specimen.

\section{Results}

3.1. External Morphology. The length of the forewing subcostal vein where the spiral organ of $H$. chloe is situated is $8 \mathrm{~mm}$, compared with the total forewing subcostal length of $29 \mathrm{~mm}$. The spiral organ, thus, occupies approximately $30 \%$ of the subcostal vein. The width of this vein is $1.1 \mathrm{~mm}$, and it has a basic shape of an elongate bottle (Figure 1(a)). The right forewing of $H$. guatemalena was drawn for the sake of comparison (Figure 1(b)).

3.2. Internal Morphology. Internally, the $H$. chloe subcostal vein possesses many thin transverse membranes called membranous discs (Md) (Figure 2(a)) which, without careful observation, appear to be touching each other and forming a very tide spiral. Although the membranous discs are separated from each other, they are slightly inclined in such a way that two discs almost touch each other on one side, but are more separated on the other, producing a slight zigzag effect (Figure 2(c)).The membranous discs are separated from each other by approximately $0.3 \mathrm{~mm}$ on one side, and they are almost in contact on the opposite side (Figure 2(b)). Moreover, each membranous disc has a large, semispherical opening at the base, and this opening is almost the same width as the base of the disc and about one third of its length. The discs are slightly curved along the longitudinal axis (Figure 2(a)).

\section{Discussion}

The $H$. chloe spiral organ seems to be similar to the one in $H$. albicornis and, to a lesser degree, to the one in $H$. atlantis. Based on this, and in characters such as the prolongation of the hind wing veins $\mathrm{M}_{3}$ and $\mathrm{Cu}_{1}$, the presence of white and black rings on the antennae, the presence of ventral red spots inside the discall cell of both wings, and distributional sympatry (in Brazil, Colombia, and Peru), it is possible that $H$. chloe and $H$. albicornis are sister species. $H$. atlantis is isolated from those two species, because it is distributed in northern Central America and is probably the sister species of the group "chloe-albicornis". These three species also share similarities in behavior in that none of them show aggressive interactions with each other or other flying objects, and none of these species has been reported to produce sounds [7].

No other species of Hamadryas shows modifications of the spiral organ like those found in these three species. In H. guatemalena, for example, the part of the subcostal vein containing the spiral organ is $47 \%$ of the wing length (almost half), whereas in $H$. chloe, it is $30 \%$ (less than a third). Also, the thickness of the spiral organ of a male of $H$. guatemalena is $0.5 \mathrm{~mm}$ [4], but in H. chloe, it is $1.1 \mathrm{~mm}$, more than double (Figures 1(a) and 1(b)). There are also important differences in the composition of the spiral organ of $H$. chloe compared with other species. In $H$. februa, for example, the spiral seems to be composed of a single spiral chain, with a space between each crest of $0.2 \mathrm{~mm}$ [4]. In H. chloe, the space between crests is also $0.2 \mathrm{~mm}$, but the width of the vein is more than double, and this makes the spiral more than twice as tight in $H$. chloe, compared with $H$. februa. 


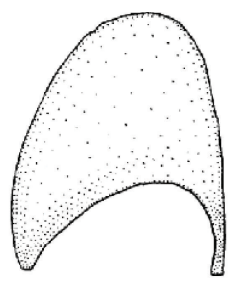

(a)

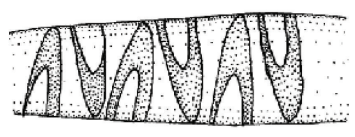

(b)

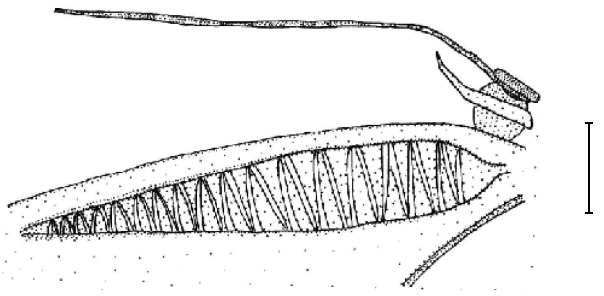

(c)

Figure 2: Spiral organ of $H$. chloe: (a) membranous internal discs, (b) internal arrangement of the membranous discs, and (c) detail of the spiral organ in the wing. Scale $1 \mathrm{~mm}$.

Evolutionary modifications like the ones described here have greater significance in phylogenetic analyses when placed in their behavioral context. The spiral organ in $H$. chloe is very different from that found in other species groups of Hamadryas, such as the $H$. februa or the $H$. feronia species groups. This is understandable, since $H$. chloe and its two related species do not produce sound signals audible to the human ear.

Phylogentetic analyses should include these morphological modifications in order to explain how this organ has evolved in the genus. Jenkins [7] placed $H$. chloe, $H$. albicornis, and $H$. atlantis in the $H$. februa species group, based on the way the forewing radial veins split. However, these veins are so close to each other, and are very thin and difficult to observe, that they could have been misinterpreted. Jenkins also states that the male genitalia of this group has the gnathos arm wide and flat on its end, but that H. albicornis is an exception. Other characters are also mentioned in Jenkins [7], but these characters are present in the other species groups of the genus, so they probably can not be considered valid synapomorphies of the species groups.

Drawings of male genitalia of all Hamadryas species are included in Jenkins [7], and only one character can be observed to be a synapomorphy of the "chloe- albicornisatlantis" species group. The vinculum in all species of Hamadryas has a very conspicuous anterior prolongation, but in these three species, the vinculum is flat, so it is an important character to be considered, since it also splits Hamadryas into two well-differentiated groups.

Careful analysis of each of these taxonomic characters will be an important tool in understanding the evolutionary relationships of the species of Hamadryas, and this will lead to a better interpretation of their distribution, ecology, and behavior.

\section{Acknowledgment}

The author would like to thank Julián Monge Nájera and Paul Hanson for providing helpful comments on the paper.

\section{References}

[1] M. Scoble, The Lepidoptera: Form, Function and Diversity, Oxford University Press, New York, NY, USA, 1992.

[2] S. L. Swihart, "Hearing in butterflies (Nymphalidae: Heliconius, Ageronia)," Journal of Insect Physiology, vol. 13, no. 3, pp. 469476, 1967.

[3] J. Monge-Nájera, "Clicking butterflies, Hamadryas, of Panama: their biology and classification (Lepidoptera, Nymphalidae)," in Insects of Panama and Mesoamerica: Selected Studies, D. Quintero and A. Aiello, Eds., pp. 567-572, Oxford University, Oxford, UK, 1992.

[4] J. Monge-Nájera, F. Hernández, M. I. González, J. Soley, J. Araya, and S. Zolla, "Spatial distribution, territoriality and sound production by tropical cryptic butterflies (Hamadryas, Lepidoptera: Nymphalidae): implications for the "industrial melanism” debate," Revista de Biologia Tropical, vol. 46, no. 2, pp. 297-330, 1998.

[5] L. R. Murillo-Hiller, "A noise producing butterfly, Iphthimoides castrensis (Nymphalidae, satyrinae) from South Brazil," Journal of the Lepidopterists' Society, vol. 60, no. 1, pp. 61-63, 2006.

[6] J. E. Yack, L. D. Otero, J. W. Dawson, A. Surlykke, and J. H. Fullard, "Sound production and hearing in the blue cracker butterfly Hamadryas feronia (lepidoptera, nymphalidae) from Venezuela," Journal of Experimental Biology, vol. 203, no. 24, pp. 3689-3702, 2000.

[7] D. W. Jenkins, "Neotropical nymphalidae-I. Revision of Hamadryas," Bulletin of the Allyn Museum, vol. 81, pp. 1-146, 1983. 

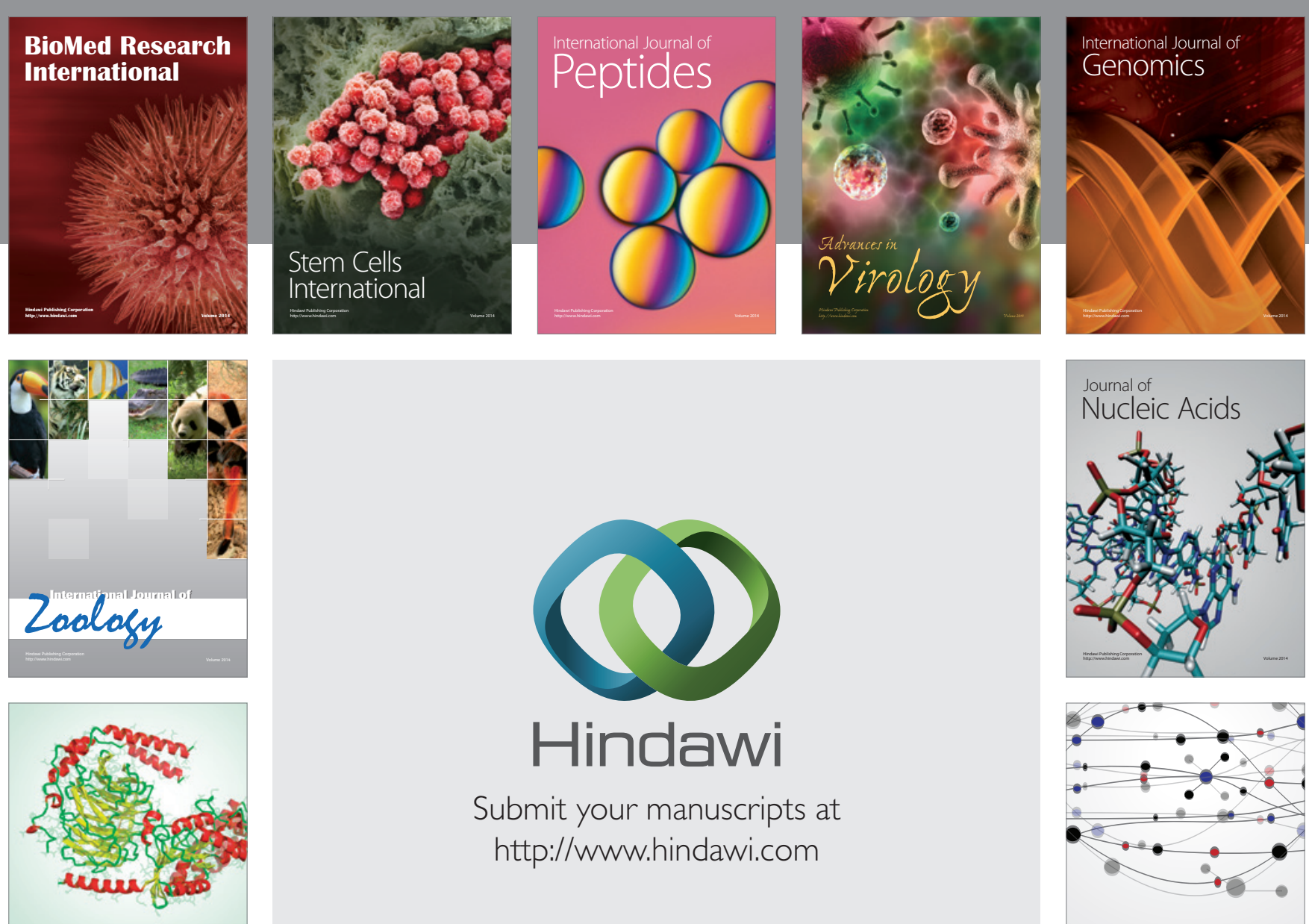

Submit your manuscripts at

http://www.hindawi.com

Signal ${ }^{\text {Jumal }}$ Transduction
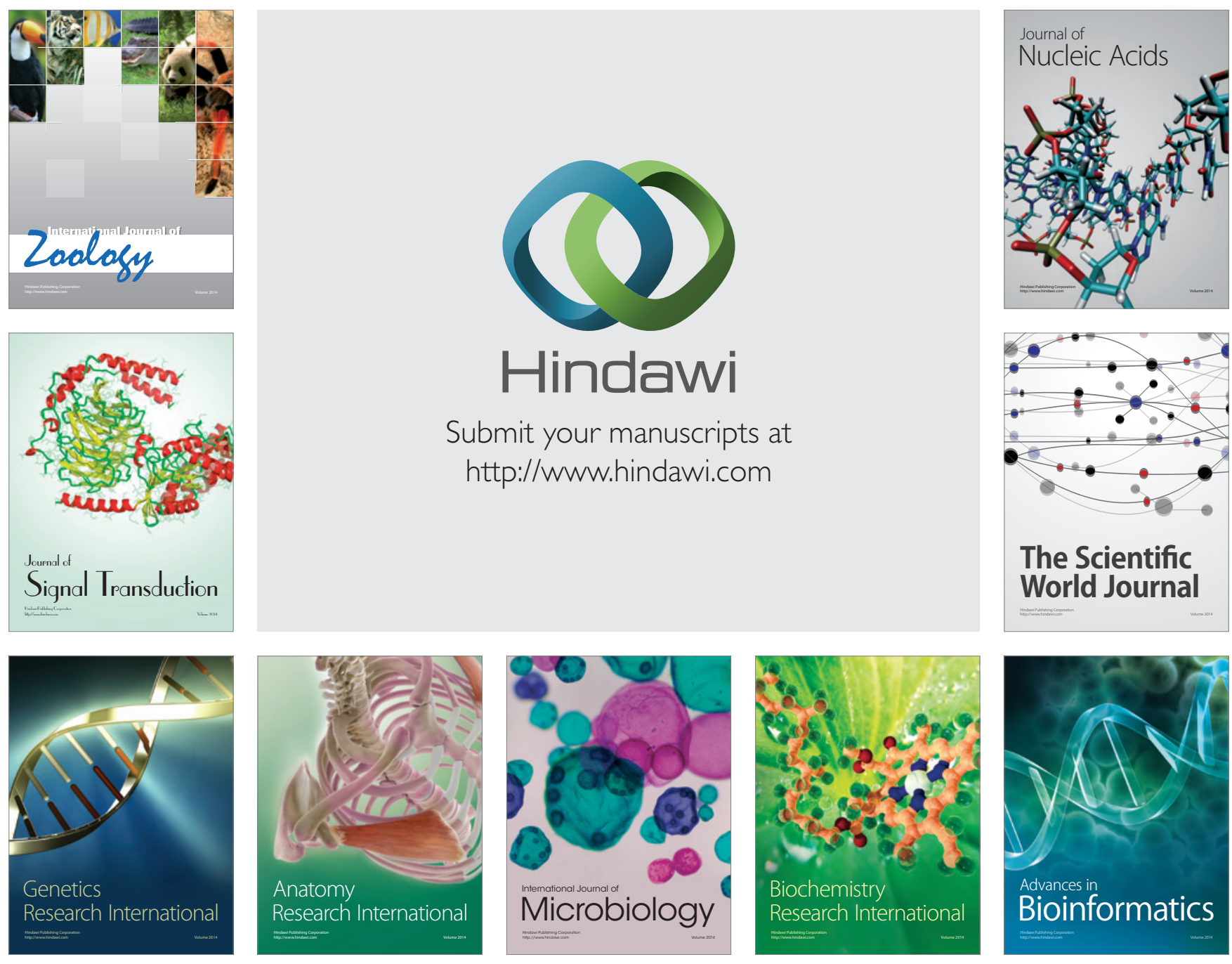

The Scientific World Journal
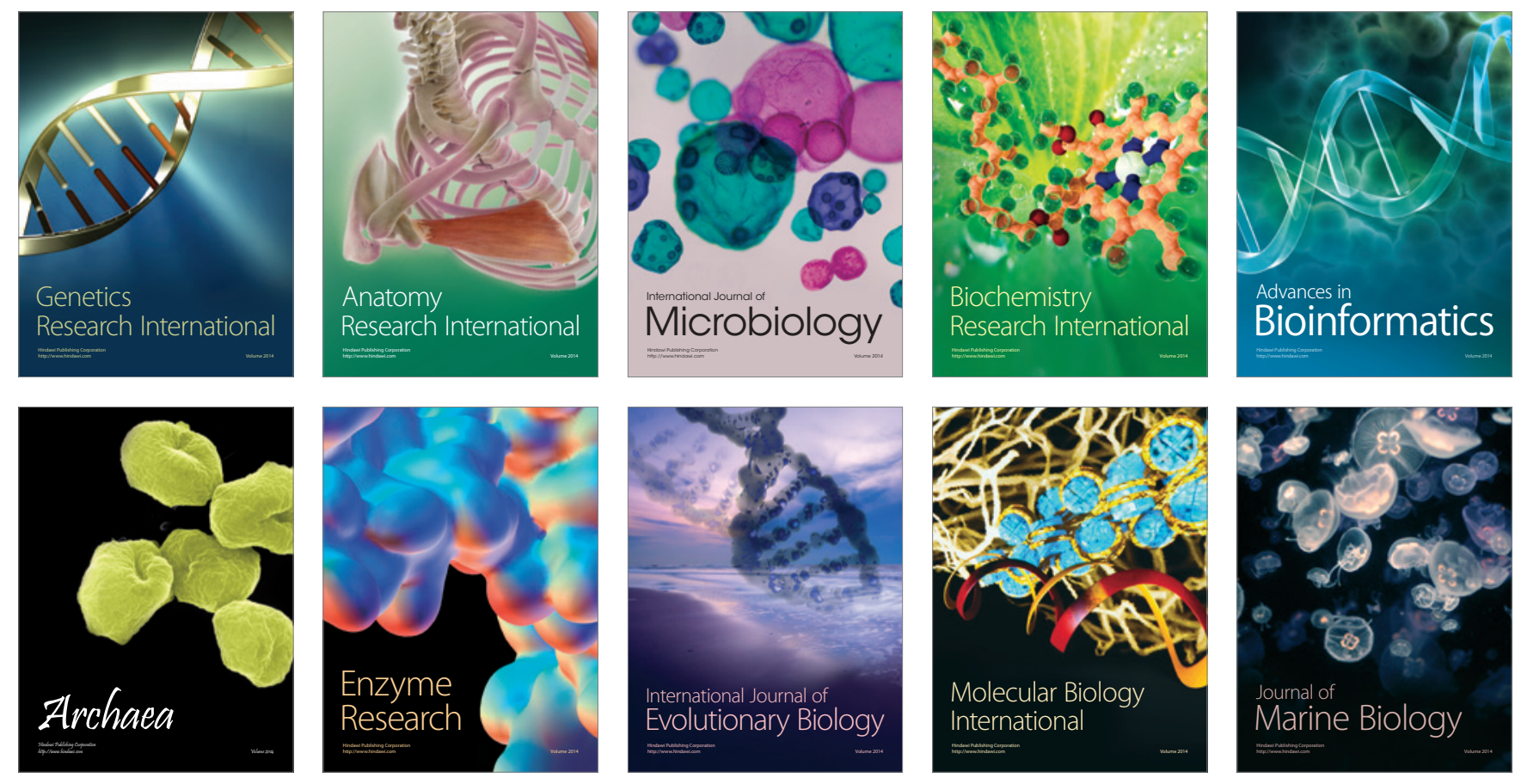